\title{
RISCO DE CRÉDITO E AS POLÍTICAS MONETÁRIAS CONVENCIONAL E NÃO CONVENCIONAL: O CASO BRASILEIRO
}

\author{
Fernanda Dantas Almeida * \\ José Angelo Divino ${ }^{\dagger}$
}

\begin{abstract}
Resumo
O crédito bancário é considerado um importante canal de transmissão de choques monetários e financeiros para o lado real da economia. Este artigo investiga a relação entre risco de crédito e a política monetária, conduzida tanto de forma convencional quanto não-convencional, e analisa os efeitos e canais de transmissão de choques exógenos no risco de crédito, taxa nominal de juros e alíquota de compulsório sobre o ciclo econômico. O modelo de Gertler \& Karadi (2011) é modificado para incorporar risco de crédito endógeno dado pela probabilidade de default em empréstimos bancários pela firma. Os resultados de simulações para a economia brasileira revelam uma taxa de default anticíclica, que compensa os bancos por perdas com os "maus" pagadores. Uma regra de compulsório anticíclica mais agressiva contribui para a estabilização do ciclo econômico sem afetar significativamente o risco de crédito.
\end{abstract}

Palavras-chave: risco de crédito, política monetária, depósitos compulsórios.

\begin{abstract}
Banking credit is an important channel of transmission of monetary and financial shocks to the real side of the economy. This paper investigates the relationship between credit risk and monetary policy, conducted in both conventional and non-conventional ways, and analyzes the effects and channels of transmission of exogenous shocks on credit risk, nominal interest rate and reserve requirements to the business cycle. The model by Gertler \& Karadi (2011) is modified to incorporate endogenous credit risk given by the probability of default in bank loans by the firm. The results of simulations for the Brazilian economy indicate a countercyclical default rate, which acts to compensate banks for losses with the "bad" payers. A more aggressive countercyclical reserve requirements rule contributes to stabilize the business cycle without significantly affecting credit risk.
\end{abstract}

Keywords: credit risk, monetary policy, reserve requirements.

JEL classification: E51, E52, G21.

DOI: http://dx.doi .org/10.11606/1980-5330/ea146034

\footnotetext{
* Universidade Católica de Brasília (UCB) e Caixa Econômica Federal (CEF). Brasília (DF), Brasil. E-mail: fdantas.almeida@gmail.com

† Universidade Católica de Brasília (UCB). Brasília (DF), Brasil. E-mail: jangelo@pos.ucb.br.
} 


\section{Introdução}

A crise financeira internacional de 2008 evidenciou que medidas convencionais de política monetária não foram suficientes para dirimir seus efeitos negativos sobre o lado real das economias afetadas, como reportam Gertler \& Karadi (2011). No Brasil, o combate aos efeitos dessa crise deu-se, entre outras, pela utilização de políticas anticíclicas de estímulo ao crescimento econômico por meio de expansão do crédito bancário. Esta política foi financiada, inicialmente, pelos bancos públicos, que praticaram sucessivas reduções nas taxas dos empréstimos de forma a aumentar o volume das concessões. Como consequência, a expansão do crédito trouxe o aumento da inadimplência, pois os bancos passaram a conceder empréstimos ${ }^{1}$. Além disso, como destacam Silva \& Divino (2013), as medidas de combate à crise também incluíram redução da oferta de títulos públicos para evitar pressão de aumento sobre as taxas de juros, substituição de swaps reversos por swaps tradicionais para atender à demanda por instrumentos de hedge no mercado de derivativos, afrouxamento do requerimento de compulsório visando regular a liquidez do sistema financeiro, incentivos fiscais para a produção de bens de consumo duráveis com o objetivo de estimular a demanda interna e preservação da liquidez bancária por meio da realização de operações compromissadas.

Diante desse reconhecimento do crédito como importante canal de transmissão de choques monetários e financeiros para o lado real da economia, este artigo investiga a relação entre risco de default e a política monetária, conduzida tanto de forma convencional, com a taxa nominal de juros servindo como instrumento de política, quanto não-convencional, com base em regras alternativas para a alíquota de requerimento compulsório. Num ambiente econômico que combina risco de crédito endógeno e políticas monetárias alternativas, são analisados os efeitos e os canais de transmissão de choques exógenos no risco de crédito, taxa nominal de juros e requerimento de compulsório sobre a estabilidade de preços e o ciclo econômico. Para tanto, o modelo de Gertler \& Karadi (2011) é modificado para incorporar risco de crédito endógeno, dado pela probabilidade da firma não pagar os empréstimos concedidos pelo banco, como sugerido por Walque et al. (2010) e aplicado por Silva \& Divino (2013) ao caso brasileiro. O requerimento de depósitos compulsórios pelo Banco Central é considerado como um instrumento de política monetária não-convencional, em conformidade com Kornelius \& Divino (2015). Esses elementos são combinados em uma modelagem unificada e usados para simular as dinâmicas de transmissão de distintos choques exógenos sobre a economia.

O modelo resultante é calibrado para a economia brasileira, que enfrentou risco de crédito e utilizou ativamente os depósitos compulsórios como instrumentos de política macroprudencial no período recente, após a adoção do regime de metas de inflação em $1999^{2}$. Inicialmente, os depósitos compulsórios foram reduzidos logo após a introdução desse regime e a consequente estabilização da inflação. O compulsório aumentou em 2002 em decorrência da incerteza do período pré-eleitoral e a forte depreciação do real. Depois,

\footnotetext{
${ }^{1}$ Vide, por exemplo, Nunes \& Portugal (2018) para uma descrição sobre a política de expansão de crédito via bancos públicos praticada pelo Brasil no período recente.

${ }^{2}$ Glocker \& Towbin (2015) apresentam uma descrição detalhada da política monetária nãoconvencional praticada pelo Banco Central do Brasil em vários episódios nos períodos imediatamente anterior e posterior à crise financeira internacional de 2008.
} 
as exigências de compulsório foram afrouxadas durante a crise financeira internacional e novamente elevadas logo em seguida, quando houve um forte crescimento do crédito. No período mais recente, os requerimentos de compulsório diminuíram devido à piora nas condições econômicas do país.

A abordagem adotada neste artigo guarda uma relação com a concepção do acelerador financeiro, segundo a qual choques adversos na economia podem ser amplificados pelo agravamento das condições do mercado financeiro, conforme originalmente proposto por Bernanke et al. (1996). Posteriormente, Bernanke et al. (1999) apresentaram a estrutura do acelerador financeiro em uma estrutura novo keynesiana, mostrando como friç̧ões no mercado de crédito podem ser incorporadas à modelagem macroeconômica. Outros autores que também investigaram o acelerador financeiro incluem Kiyotaki \& Moore (1997), Carlstrom \& Fuerst (1997), Christensen \& Dib (2008) e De Graeve (2008).

Posteriormente, Kiyotaki \& Moore (2019), Gerali et al. (2010), Cúrdia \& Woodford (2010), inovaram ao considerar friç̧ões financeiras no nível dos intermediários financeiros e não no nível das firmas, como era a prática comum. Gertler \& Karadi (2011), com base em Christiano et al. (2005) e Smets \& Wouters (2007), desenvolveram uma abordagem com foco na política monetária não convencional adotada pelos Estados Unidos para fazer face à crise de 2007-2008. Inovaram ao considerar explicitamente a intermediação financeira diretamente exercida pelo Federal Reserve (Fed) como instrumento de política monetária não convencional, além de incorporar fricções no âmbito dos intermediários financeiros.

Para o Brasil, há diversas aplicações da modelagem DSGE, embora a estrutura do acelerador financeiro ainda seja pouco explorada. Castro et al. (2015) desenvolveram um modelo DSGE de grande escala, combinando características usuais da abordagem novo keynesiana, como rigidez de preços e salários e custos de ajustamento, com características específicas da economia brasileira. Para avaliar a interação entre as políticas fiscal e monetária, Valli \& Carvalho (2010) estendem o modelo europeu New Area-Wide Model (NAWM), ampliando o escopo da política fiscal e permitindo heterogeneidade no mercado de trabalho. Já Valli \& Carvalho (2011) consideram não somente metas de saldo primário, mas também incorporam à modelagem despesas cíclicas e programas sociais sob a forma de transferências públicas, investimento público e tributação distorciva.

Kornelius \& Divino (2015) modificaram o arcabouço de Gertler \& Karadi (2011) para introduzir a exigência de depósitos compulsórios pela Autoridade Monetária e um choque de confiança dos depositantes no sistema financeiro. Encontraram que o requerimento de compulsório afeta a dinâmica de propagação e amplifica os efeitos de choques exógenos por meio do canal do crédito. Nessa mesma linha, Areosa \& Coelho (2013) verificaram que o impacto da redução da alíquota do recolhimento compulsório possui efeitos semelhantes aos de uma redução na taxa básica de juros, porém quantitativamente menores.

Em uma abordagem mais ampla, Tavman (2015) analisou os efeitos de políticas macroprudenciais anticíclicas num modelo à la Gertler \& Karadi (2011), em que o recolhimento compulsório está entre os instrumentos macroprudenciais. Carvalho \& Castro (2016) também analisaram os papéis de instrumentos macroprudenciais anticíclicos alternativos, dentre eles o recolhimento compulsório, em estudo aplicado ao caso brasileiro. Já Agénor et al. 
(2018) exploraram a política macroprudencial baseada em recolhimentos compulsórios anticíclicos em um ambiente de economia aberta.

O risco de crédito é explorado por Silva \& Divino (2013), que examinaram os canais de transmissão da crise financeira para o lado real da economia. $\mathrm{O}$ modelo utilizado incluiu o setor financeiro e analisou os efeitos do risco de crédito no pagamento dos empréstimos bancários por parte das firmas e um choque na liquidez ocasionado por saques não antecipados nos depósitos. Além disso, analisaram a eficiência das instituições financeiras, considerando que o banco transforma os recursos captados em crédito por meio de uma tecnologia de produção. Os resultados indicaram que a taxa de pagamento dos empréstimos é pró-cíclica e o risco de default depende de características estruturais.

O presente estudo contribui com a literatura ao obter endogenamente a probabilidade de default das firmas na presença de heterogeneidade, admitindo que as firmas são heterogêneas no risco de crédito. O bloco de firmas pode ser visto como um caso intermediário entre a situação em que elas sempre pagam suas dívidas e praticam default ao estilo de Walque et al. (2010) e Silva \& Divino (2013). O ambiente da política monetária também é enriquecido com a prática de políticas convencionais e não-convencionais, representando melhor a atuação da Autoridade Monetária no período recente. Ademais, ao trazer duas taxas de juros distintas para diferentes tomadores de crédito, chamados de "bons" e "maus" pagadores, o modelo permite analisar como a qualidade dos mutuários impacta na taxa de juros dos empréstimos.

Os resultados indicam a existência de uma relação negativa entre a taxa de juros da economia e a taxa de pagamento dos empréstimos que funciona como uma compensação ao banco por perdas com o default dos "maus" pagadores. O custo mais elevado para o crédito, devido ao risco de default, resulta em efeitos mais danosos para a economia em termos de queda do produto. Adicionalmente, considerando as políticas monetárias convencional e não-convencional, as simulações revelam que alíquotas maiores e remunerações menores para os depósitos compulsórios trazem efeitos recessivos mais severos para o produto da economia na presença de um choque de política monetária. Isso ocorre porque tais choques ampliam a inadimplência das firmas, amplificando seus efeitos negativos sobre o crédito e o lado real da economia. Já sobre a inflação, as respostas dinâmicas indicam que os efeitos de alterações na alíquota ou na remuneração dos depósitos compulsórios são limitados, resultado coerente com os impactos recessivos mais pronunciados sobre a atividade econômica.

Este artigo está organizado do seguinte modo. A segunda seção apresenta o modelo teórico base e discorre sobre as alterações realizadas nesse modelo. A terceira seção reporta os resultados de choques na política monetária, na taxa de pagamento dos empréstimos e na alíquota dos requerimentos compulsórios. Por fim, a quarta seção trata das observações conclusivas.

\section{Modelo}

O arcabouço de Gertler \& Karadi (2011) foi escolhido como referência básica por incorporar diretamente o sistema bancário em um ambiente com fricção financeira e favorecer a análise dos efeitos combinados das políticas monetária, via taxa básica de juros, e macroprudencial, por meio de recolhimentos 
compulsórios, sobre o lado real da economia. Assim, foi possível introduzir o risco de crédito na intermediação financeira de modo a avaliar as consequências do não pagamento de empréstimos por parte das firmas sobre o balanço dos bancos e a repercussão desse comportamento sobre as demais variáveis endógenas da economia. O requerimento de depósitos compulsórios pela $\mathrm{Au}$ toridade Monetária foi acrescido à estrutura original do modelo, pois essa modificação já se mostrou relevante ao caso brasileiro na aplicação realizada por Kornelius \& Divino (2015).

Outros modelos da literatura de fricções financeiras, como Bernanke et al. (1999), Iacoviello (2005), Gerali et al. (2010), dentre outros, também incorporam risco de crédito que afeta o lado real da economia e incluem, de maneiras distintas, o sistema bancário. Optamos por Gertler \& Karadi (2011) porque a fricção financeira é inserida diretamente no setor de intermediação financeira, por meio de uma restrição à capacidade dos bancos emprestarem que tem origem em seus próprios balanços. Como destacam Kornelius \& Divino (2015), essa característica o distancia de abordagens que limitam a capacidade de emprestar dos bancos por meio de restrições colocadas sobre os tomadores dos empréstimos, como o requerimento de colateral. Adicionalmente, as taxas de juros de captação e de empréstimos, bem como o spread entre elas, saem como variáveis endógenas ao modelo. Outras abordagens, incluindo formas alternativas de se modelar o risco de crédito, também já incorreram em aplicações diretas à economia brasileira, podendo ser encontrados, por exemplo, em Ferreira \& Nakane (2015), Carvalho \& Castro (2016) e Carvalho et al. (2014).

Como a versão original do modelo é bastante conhecida na literatura, tendo sido ampliada e modificada em diversas dimensões, omite-se a sua apresentação, que pode ser encontrada em Gertler \& Karadi (2011). Descreve-se, a seguir, as modificações realizadas no modelo-base, a saber, introdução de requerimentos compulsórios e risco de crédito.

\subsection{Requerimento de Depósitos Compulsórios}

A inclusão do requerimento de depósitos compulsórios é realizada conforme Montoro \& Tovar (2010), que já foi aplicada ao caso brasileiro por Kornelius \& Divino (2015). Dessa forma, considera-se que a Autoridade Monetária recolha uma fração dos depósitos recebidos pelos bancos, de modo a interferir no nível de liquidez da economia. Então, sendo $B_{j t+1}$ o volume de depósitos captados no período $t$ pelo banco $j$, assume-se que os bancos devam recolher, no mesmo período da captação, o montante $R R_{j t}$ sob a forma de reservas bancárias. Sejam $Q_{t}$ o preço do crédito, $S_{j t}$ a quantidade de crédito concedido às firmas não financeiras e $N_{j t}$ a riqueza do banqueiro $j$ no fim do período $t$. O balanço dos bancos é dado por:

$$
Q_{t} S_{j t}+R R_{j t}=N_{j t}+B_{j t+1}
$$

onde $R R_{j t}=\tau_{t} B_{j t+1}, 0<\tau_{t}<1$.

Da equação (1), obtém-se a seguinte expressão para $B_{j t+1}$ :

$$
B_{j t+1}=\frac{1}{\left(1-\tau_{t}\right)}\left(Q_{t} S_{j t}-N_{j t}\right)
$$


O requerimento compulsório atua retirando liquidez da economia, pois, para um mesmo nível de depósitos, a concessão de empréstimos fica reduzida. Caso uma instituição financeira deseje manter o nível de concessões, deve realizar uma captação maior.

Com essa alteração, a evolução do capital bancário fica:

$$
N_{j t+1}=R_{k t+1} Q_{t} S_{j t}+R_{R R, t+1} \tau_{t} B_{j t+1}-R_{t+1} B_{j t+1}
$$

Onde $R_{k t+1}$ é a taxa de juros cobrada em $t+1$ pelos empréstimos realizados em $t, R_{t+1}$ é a taxa paga em $t+1$ aos depósitos realizados em $t, R_{R R, t+1}$ é a remuneração do requerimento compulsório, sendo $R_{R R t}=\kappa_{R R} R_{t} \operatorname{com} 0 \leq$ $\kappa_{R R} \leq 1$.

Substituindo $B_{j t+1}$ de (2) em (3):

$$
N_{j t+1}=\left[R_{k t+1}-\frac{R_{t+1}-\tau_{t} R_{R R, t+1}}{1-\tau_{t}}\right] Q_{t} S_{j t}+\left[\frac{R_{t+1}-\tau_{t} R_{R R, t+1}}{1-\tau_{t}}\right] N_{j t}
$$

Defina:

$$
R_{t+1}^{*}=R_{t+1}+\frac{\tau_{t}}{1-\tau_{t}}\left(R_{t+1}-R_{R R, t+1}\right)
$$

Nota-se que a taxa $R_{t+1}^{*}$ corresponde à taxa de remuneração dos depósitos, $R_{t+1}$, mais um incremento positivo ${ }^{3}, \frac{\tau_{t}}{\left(1-\tau_{t}\right.}\left(R_{t+1}-R_{R R, t+1}\right)$. Esse incremento corresponde à diferença entre a própria taxa de remuneração dos depósitos das famílias e a remuneração do depósito compulsório. Assim, o depósito compulsório pode ser interpretado como um custo incremental que encarece o custo total do funding do banco $R_{t+1}^{*}$.

Nesse caso, a evolução do capital próprio da instituição financeira é dada por:

$$
N_{j t+1}=\left[R_{k t+1}-R_{t+1}^{*}\right] Q_{t} S_{j t}+R_{t+1}^{*} N_{j t}
$$

A evolução do capital do banco continua semelhante. Entretanto, no lugar da taxa paga aos depósitos, há uma taxa modificada que contempla o requerimento compulsório e que pode ser interpretada como o custo total do funding da instituição financeira.

Algumas observações podem ser realizadas sobre o requerimento compulsório. Caso $\tau_{t}>0$ e $R_{t}=R_{R R, t}$, o compulsório continua atuando de modo a retirar liquidez da economia, entretanto, seu valor não impacta na gestão de ativos e passivos do banco, pois $R_{t+1}^{*}=R_{t+1}$. Por outro lado, se $\tau_{t}>0$ e $R_{t}>R_{R R, t}$, a estratégia do banco deve ser revisada, tendo em vista que $R_{t+1}^{*}>R_{t+1}$ terá impactos sobre o nível de alavancagem da instituição ${ }^{4}$.

\footnotetext{
${ }^{3}$ Seja $0<\tau_{t}<1$ e $R_{R R, t}=\kappa_{R R} R_{t}$ onde $0 \leq \kappa_{R R} \leq 1$, então $\frac{\tau_{t}}{1-\tau_{t}}\left(R_{t+1}-R_{R R, t+1}\right) \geq 0$.

${ }^{4}$ Se $\tau_{t}>0$ e $R_{t}>R_{R R, t}$, então $R_{t+1}^{*}>R_{t+1}$ e o banco terá a remuneração dos ativos reduzida e a remuneração do capital próprio elevada conforme $N_{j t+1}=\left[R_{k t+1}-R_{t+1}^{*}\right] Q_{t} S_{j t}+R_{t+1}^{*} N_{j t}$. Assim, o banco pode preferir reduzir as concessões de crédito, o que implica em um menor índice de alavancagem: $\phi_{t}=\frac{Q_{t} S_{j t}}{N_{j t}}$.
} 
Conforme Montoro \& Tovar (2010) e seguindo Kornelius \& Divino (2015), serão consideradas duas possibilidades de especificação para o nível dos depósitos compulsórios. A primeira considera um nível fixo e a segunda uma regra anticíclica em relação ao crédito, na qual o nível do compulsório aumenta quando o crédito ultrapassa o seu valor de equilíbrio e reduz no caso oposto. Assim, temos que:

$$
\tau_{t}=\left\{\begin{array}{c}
\bar{\tau} \\
\bar{\tau}+\kappa_{\tau}\left(\log Q_{t} S_{t}-\log Q_{t}^{*} S_{t}\right)
\end{array}\right.
$$

onde $\bar{\tau}$ indica o valor fixo da alíquota dos depósitos compulsórios, $\kappa_{\tau}$ caracteriza o peso que a Autoridade Monetária atribui aos desvios do nível de crédito em relação ao seu nível de estado estacionário. Visando captar alterações inesperadas de política, é considerado um choque exógeno na regra para a alíquota dos depósitos compulsórios, de tal forma que:

$$
\tau_{t}=\bar{\tau}+\kappa_{\tau}\left(\log Q_{t} S_{t}-\log Q_{t}^{*} S_{t}\right)+\epsilon_{\tau_{t}}
$$

onde $\epsilon_{\tau_{t}}$ é um processo AR(1) estacionário.

\subsection{Risco de Crédito}

A modelagem original de Walque et al. (2010) é modificada com a introdução de um risco endógeno no mercado de crédito. Uma parte das firmas intermediárias, que se defrontam com custos de agência, podem optar por não repagarem seus empréstimos. Deferentemente de Walque et al. (2010), onde todos os tomadores de crédito podem dar default parcial em sua dívida, assumimos que há dois tipos de tomadores de empréstimos, sendo que um deles nunca pratica default. As firmas consideradas "más pagadoras" (ou tipo 1) incorrem em uma penalidade em sua função lucro caso optem pelo default (parcial ou total) em seus empréstimos. Dessa forma, a firma deve escolher estrategicamente a taxa de pagamento de forma a maximizar o seu lucro. $\mathrm{O}$ custo com default pode ser visto como uma penalidade na taxa de juros das concessões, encarecendo os empréstimos e dificultando a obtenção de novos financiamentos.

\section{Firmas Produtoras de Bens Intermediários}

Considera-se um continuum de firmas produtoras de bens intermediários com medida 1 . No início do período $t$, o produtor de cada firma adquire capital $K_{t}$ para utilizar na produção do mesmo período ${ }^{5}$ conjuntamente com o trabalho, conforme a seguinte função:

$$
Y_{m t}=A_{t} K_{t}^{\alpha} L_{t}^{1-\alpha}
$$

\footnotetext{
${ }^{5}$ Para que a taxa de juros dos empréstimos possa ser obtida como solução do problema, considera-se que a firma adquire capital $K_{t}$ em $t$ e o utiliza ainda em $t$.
} 
As firmas financiam a compra do capital por meio da obtenção de fundos nas instituições financeiras. Assim, a firma obtém recursos, $S_{t}$, igual à quantidade de capital adquirida, $K_{t}$, ao preço $Q_{t}$ por unidade. Isto é,

$$
Q_{t} K_{t}=Q_{t} S_{t}
$$

Dado que os empréstimos têm maturidade de um período, se a firma tomar emprestado $Q_{t} S_{t}$ em $t$ para financiar a aquisição de capital, em $t+1$ ela deverá pagar o montante $R_{k t+1} Q_{t} S_{t}$, correspondente ao valor inicial corrigido pela taxa de juros $R_{k t+1}$. Cabe ressaltar que essa taxa será definida somente no período em que ocorrerá o pagamento do empréstimo, em $t+1$.

Há dois tipos de firmas: tipo 1 (ou "más" pagadoras) que incorrem em risco de default e tipo 2 (ou "boas" pagadoras) que não incorrem nesse risco. Então, para a firma do tipo 1 é considerada a existência de fricção na concessão de empréstimos. Assim, seja $\left(1-p g_{t}\right)$ a probabilidade da firma tipo 1 não pagar no período $t$ o empréstimo obtido em $(t-1)$. Logo, $p g_{t}$ representa a probabilidade de pagamento escolhida por essa firma, onde $p g_{t} \in(0,1)$. Como consequência da probabilidade de não pagamento da dívida, esta firma incorre em um custo quadrático, dado por $\frac{\kappa_{D}}{2}\left[\left(1-p g_{t-1}\right)\left(R_{k t-1}^{M}+\delta\right) Q_{t-1} K_{t-1}\right]^{2}$, que a penaliza pelo descumprimento das obrigações financeiras referentes ao empréstimo tomado no período anterior. O problema da firma tipo 1 consiste da maximização do valor presente esperado do fluxo de lucros futuros, no qual ela escolhe a demanda por mão-de-obra, o capital ${ }^{6}$ e a taxa de pagamento dos empréstimos:

$$
\max _{\left\{L_{t}, K_{t}, p g_{t}\right\}_{t=i}^{\infty}} E_{t}\left\{\sum_{i=0}^{\infty} \beta^{i} \Lambda_{t, t+i} \Pi_{m t+i}\right\}
$$

sujeito a:

$$
\begin{array}{r}
\Pi_{m t}=P_{m t} Y_{m t}-W_{t} L_{t}-\exp \left(\varepsilon_{t}^{p g}\right) p g_{t}\left(R_{k t}^{M}+\delta\right) Q_{t} K_{t} \\
-\frac{\mathcal{K}_{D}}{2}\left[\left(1-\exp \left(\varepsilon_{t-1}^{p g}\right) p g_{t-1}\right)\left(R_{k t-1}^{M}+\delta\right) Q_{t-1} K_{t-1}\right]^{2}
\end{array}
$$

onde $P_{m t} Y_{m t}$ é a receita da firma, $W_{t} L_{t}$ corresponde à despesa com salários, $\exp \left(\varepsilon_{t}^{p g}\right) p g_{t}\left(R_{k t}^{M}+\delta\right) Q_{t} K_{t}$ é o custo do capital após a reposição da depreciação, sendo $R_{k t}^{M}$ a taxa de juros que será definida quando do pagamento do empréstimo em $t+1, p g_{t}$ a probabilidade de pagamento dos empréstimos e $\varepsilon_{t}^{p g}$ um choque exógeno na taxa de pagamento, e $\frac{\kappa_{D}}{2}\left[\left(1-\exp \left(\varepsilon_{t-1}^{p 8}\right) p g_{t-1}\right)\left(R_{k t-1}^{M}+\right.\right.$ $\left.\delta) Q_{t-1} K_{t-1}\right]^{2}$ é o custo com o default (não pagamento) incidente sobre a parcela de crédito inadimplente do período anterior. Nota-se que, no período corrente, a firma decide o quanto deve pagar do empréstimo adquirido para maximizar o lucro. Como consequência, o montante que não foi pago afeta

\footnotetext{
${ }^{6}$ Para que seja possível obter a taxa de juros dos empréstimos na solução do problema, a firma escolhe a quantidade de capital utilizado na produção, diferente do modelo original de Gertler \& Karadi (2011), no qual ela escolhe a taxa de utilização do capital, considerando que o capital disponível para a produção, $K_{t}$, já está dado pelos empréstimos tomados no período anterior. Além disso, nessa versão modificada do modelo, a depreciação é um parâmetro fixo e não uma função da taxa de utilização do capital.
} 
negativamente o lucro do período seguinte. Assim, o custo com default pode ser visto como uma penalidade na taxa de juros das concessões, agindo de forma a encarecer os empréstimos e podendo dificultar a obtenção de novos financiamentos. Essa estrutura baseia-se em Walque et al. (2010), tendo sido aplicada ao caso brasileiro por Silva \& Divino (2013) por meio de um modelo RBC (Real Business Cycles), no qual não havia fricções financeiras e nem políticas monetárias alternativas.

Como solução desse problema, obtêm-se a demanda por trabalho, a taxa ótima de default e a taxa de juros aplicada aos empréstimos, representadas por:

$$
\begin{gathered}
P_{m t}(1-\alpha) \frac{Y_{m t}}{L_{t}}=W_{t} \\
1=E_{t}\left\{\beta \Lambda_{t, t+1} \kappa_{D}\left[\left(1-\exp \left(\varepsilon_{t}^{p g}\right) p g_{t}\right)\left(R_{k t}^{M}+\delta\right) Q_{t} K_{t}\right]\right\} \\
E_{t}\left[\beta \Lambda_{t, t+1} R_{k t+1}^{M}\right]=\frac{\alpha P_{m t} Y_{m t}}{\exp \left(\varepsilon_{t}^{p g}\right) p g_{t} Q_{t} K_{t}}-\delta
\end{gathered}
$$

A equação (9) indica que a demanda por trabalho permanece idêntica ao problema original de Gertler \& Karadi (2011). A equação (10) representa o custo marginal de default pago pela firma no caso de retenção de uma unidade de investimento corrente, ampliada pelo choque exógeno na taxa de pagamento. A equação (11) revela a taxa de juros aplicada aos empréstimos alterada para considerar a probabilidade de pagamento dos empréstimos. Cabe salientar que, conforme (11), a probabilidade de pagamento, $p g_{t}$, bem como choques exógenos positivos sobre essa probabilidade, geram efeitos negativos sobre os juros dos empréstimos, de forma que um aumento em $p g_{t}$, provoca queda em $R_{k t+1}^{M}$. Alternativamente, um aumento no default, $\left(1-p g_{t}\right)$, implica em elevação da taxa de juros dos empréstimos. Isso ocorre porque, conforme Walque et al. (2010), os bancos estão interessados no retorno líquido dos empréstimos, que depende positivamente da taxa de pagamento.

Para permitir a análise de perturbações na taxa de pagamento, o choque exógeno $\varepsilon_{t}^{p g}$ é modelado como um processo $\mathrm{AR}(1)$ estacionário, tal que:

$$
\varepsilon_{t}^{p g}=\rho_{p} \varepsilon_{t-1}^{p g}+\xi
$$

onde $0<\rho_{p}<1 e \xi \simeq \operatorname{iid}\left(0, \sigma_{\xi}^{2}\right)$.

Como a firma do tipo 2 não incorre em risco de default, seu problema consiste da escolha do capital que será utilizado na produção e da quantidade de trabalho:

$$
\max _{\left\{L_{t}, K_{t}\right\}_{t=i}^{\infty}} E_{t}\left\{\sum_{i=0}^{\infty} \beta^{i} \Lambda_{t, t+i} \Pi_{m t+i}\right\}
$$

sujeito a: 


$$
\Pi_{m t}=P_{m t} Y_{m t}-W_{t} L_{t}-\left(R_{k t}^{B}+\delta\right) Q_{t} K_{t}
$$

De modo similar ao caso anterior, a solução resulta na demanda por trabalho e na taxa de juros aplicada aos empréstimos:

$$
\begin{gathered}
P_{m t}(1-\alpha) \frac{Y_{m t}}{L_{t}}=W_{t} \\
E_{t}\left[\beta \Lambda_{t, t+1} R_{k t+1}^{B}\right]=\frac{\alpha P_{m t} Y_{m t}}{Q_{t} K_{t}}-\delta
\end{gathered}
$$

Comparando $R_{k t}^{M}$ e $R_{k t}^{B}$, por meio das equações (11) e (14), nota-se que a taxa de juros aplicada aos empréstimos às firmas do tipo 1 contempla a probabilidade de pagamento, sendo que $p g_{t} \in(0,1)$ implica em $R_{k t}^{M}>R_{k t}^{B}$, de modo a compensar o banco pela perda de receita decorrente do default praticado por algumas firmas ${ }^{7}$.

\section{Instituições Financeiras}

Com a possibilidade de default por parte das firmas e dado que o empréstimo concedido em um período somente será pago no período posterior, o balanço da instituição financeira no período $t$ não é afetado, permanecendo $Q_{t} S_{j t}+$ $R R_{j t}=N_{j t}+B_{j t+1}$.

Considere, agora, que $\rho_{k} \in[0,1]$ represente a parcela das firmas do tipo 1 , que podem não pagar os empréstimos e, por essa razão, incorrem na taxa de juros sobre empréstimos $R_{k t}^{M}$ e no custo de default $\frac{\kappa_{D}}{2}\left[\left(1-p g_{t-1}\right) R_{k t-1}^{1} Q_{t-1} K_{t-1}\right]^{2}$. De forma complementar, $\left(1-\rho_{k}\right)$ refere-se à parcela das firmas do tipo 2 , que cumprem com suas obrigações financeiras, pagando pelos empréstimos $S_{t}$ à taxa de juros $R_{k t}^{B}$. Assim, a evolução do patrimônio líquido do banco em $(t+1)$ será de:

$$
N_{j t+1}=\left[\rho_{k} R_{k t+1}^{M}+\left(1-\rho_{k}\right) R_{k t+1}^{B}\right] Q_{t} S_{j t}+R_{R R, t+1} \tau_{t} B_{j t+1}-R_{t+1}
$$

Seja $R_{k t+1}^{*}=\rho_{k} R_{k t+1}^{M}+\left(1-\rho_{k}\right) R_{k t+1}^{B}$ a taxa de juros agregada sobre os empréstimos. Logo:

$$
N_{j t+1}=R_{k t+1}^{*} Q_{t} S_{j t}+R_{R R, t+1} \tau_{t} B_{j t+1}-R_{t+1}
$$

Substituindo $B_{j t+1}=\frac{1}{\left(1-\tau_{t}\right)}\left(Q_{t} S_{j t}-N_{j t}\right)$ em (15), a evolução do capital bancário é dada por:

\footnotetext{
${ }^{7}$ Assumimos que as firmas do tipo 2, que nunca praticam default, não mudam para o grupo de firmas do tipo 1, que podem praticar default, por simplicidade. Mas, mesmo com essa hipótese, os grupos de firmas podem se alterar dependendo da escolha feita pelas firmas do tipo 1 sobre a taxa de pagamento. Se elas escolherem, por exemplo, pagar integralmente os empréstimos, teremos somente firmas do tipo 2 na economia. O oposto ocorreria se elas escolhessem praticar default e o grupo de firmas do tipo 2 fosse arbitrariamente pequeno. Vale lembrar que as firmas do tipo 1 sofrem uma penalidade nos lucros quando escolhem praticar default.
} 


$$
N_{j t+1}=\left[R_{k t+1}^{*}-R_{t+1}^{*}\right] Q_{t} S_{j t}+R_{t+1}^{*} N_{j t}
$$

Com essas alterações, o problema das instituições financeiras continua sendo maximizar o valor esperado descontado de sua riqueza, porém, considerando as novas taxas de juros, $R_{k t+1}^{*}$ e $R_{t+1}^{*}$ :

$$
V_{j t}=\max E_{t} \sum_{i=0}^{\infty}(1-\theta) \theta^{i} \beta^{i+1} \Lambda_{t, t+1+i}\left(N_{j t+1+i}\right)
$$

Logo, tem-se $V_{j t}=v_{t} Q_{t} S_{j t}+\eta_{t} N_{j t}$, com:

$$
\begin{gathered}
v_{t}=E_{t}\left\{(1-\theta) \beta \Lambda_{t, t+1}\left(R_{k t+1}^{*}-R_{t+1}^{*}\right)+\beta \Lambda_{t, t+1} \theta x_{t, t+1} v_{t+1}\right\} \\
\eta_{t}=E_{t}\left\{(1-\theta) \beta \Lambda_{t, t+1} R_{t+1}^{*}+\beta \Lambda_{t, t+1} \theta z_{t, t+1} \eta_{t+1}\right\}
\end{gathered}
$$

onde $x_{t, t+1} \equiv Q_{t+i} S_{j t+i} / Q_{t} S_{j t}$ representando a taxa bruta de crescimento dos ativos e $z_{t, t+1} \equiv N_{j t+i} / N_{j t}$ a taxa bruta de crescimento do capital próprio.

$O$ índice de alavancagem do banco continua:

$$
\phi_{t}=\frac{Q_{t} S_{j t}}{N_{j t}}
$$

e a evolução do capital próprio do banco permanece dada por:

$$
N_{j t+1}=\left[\left(R_{k t+1}^{*}-R_{t+1}^{*}\right) \phi_{t}+R_{t+1}^{*}\right] N_{j t}
$$

$\operatorname{com} z_{t, t+1}=N_{j t+1} / N_{j t}=\left(R_{k t+1}^{*}-R_{t+1}^{*}\right) \phi_{t}+R_{t+1}^{*}$ e $x_{t, t+1}=Q_{t+i} S_{j t+i} / Q_{t} S_{j t}$ $=\left(\phi_{t+1} / \phi_{t}\right) z_{t, t+1}$.

A oferta total de crédito da economia mantém-se em:

$$
Q_{t} S_{t}=\phi_{t} N_{t}
$$

onde $S_{t}$ e $N_{t}$ representam, respectivamente, a soma do crédito e do capital próprio dos bancos da economia.

Por fim, a evolução do patrimônio líquido agregado dá-se pela soma do capital próprio dos bancos já existentes, $N_{e t}$, e dos novos bancos, $N_{n t}$ :

$$
N_{t}=\theta\left[\left(R_{k t}^{*}-R_{t}^{*}\right) \phi_{t}+R_{t}^{*}\right] N_{t-1}+\omega Q_{t-1} S_{t-1}
$$

onde: $N_{e t}=\theta\left[\left(R_{k t}^{*}-R_{t}^{*}\right) \phi_{t}+R_{t}^{*}\right] N_{t-1}$ e $N_{n t}=\omega Q_{t-1} S_{t-1}$. 


\subsection{Política Monetária}

A política monetária convencional é caracterizada por uma Regra de Taylor com suavização da taxa de juros:

$$
i_{t}=(1-\rho)\left[i+k_{\pi} \pi_{t}+k_{y}\left(\log Y_{t}-\log Y_{t}^{*}\right)\right]+\rho i_{t-1}+\epsilon_{i_{t}}
$$

onde $\rho \in(0,1)$ é o parâmetro de suavização da taxa de juros, $i_{t}$ é a taxa de juros nominal, $i$ é a taxa de juros nominal no estado estacionário, $Y_{t}^{*}$ é o nível de produto natural e $\epsilon_{i_{t}} \approx i i d\left(0, \sigma_{\epsilon_{i}}^{2}\right)$ é um choque exógeno na política monetária. A relação entre a taxa de juros nominal e real é dada pela Equação de Fisher:

$$
1+i_{t}=R_{t+1} \frac{E_{t} P_{t+1}}{P_{t}}=R_{t+1} \pi_{t+1}
$$

\section{Resiltados}

\subsection{Calibração}

O modelo é calibrado para a economia brasileira visando avaliar a dinâmica das variáveis endógenas resultante de distintos choques exógenos. Para a calibração, utilizou-se da literatura nacional sempre que possível. A Tabela 1 resume os valores utilizados e descreve as respectivas fontes. Considerou-se Castro et al. (2015) para os parâmetros da Regra de Taylor, do reajuste dos preços dos bens finais, da taxa de desconto intertemporal e dos hábitos do consumo. Silva \& Divino (2013) foram base para os valores da participação do trabalho na utilidade das famílias, do inverso da elasticidade de Frish da oferta de trabalho, da intensidade do custo de default e da participação do capital na função de produção. Os parâmetros referentes à depreciação do capital vieram de Cavalcanti \& Vereda (2011) e os parâmetros das instituições financeiras tiveram origem em Kornelius \& Divino (2015). Os parâmetros não encontrados na literatura nacional foram extraídos de Gertler \& Karadi $(2011)^{8}$.

A parcela dos empréstimos sobre a qual incide o risco de default, $\rho_{k}$, é calibrada como a razão entre a soma dos empréstimos classificados em ratings diferentes de $\mathrm{AA}^{9}$ e o total de empréstimos realizados pelo SFN, conforme Balancete dos Bancos de 01/2016 publicado pelo Banco Central do Brasil. Embora essa estratégia implicitamente assuma que firmas bem avaliadas não tem incentivos ao default, não é óbvia em termos empíricos, já que mesmo firmas bem avaliadas também podem dar default. Contudo, consideramos que firmas bem avaliadas resistam ao default em empréstimos por receio de perda de seu rating superior e pela sinalização negativa que transmitiriam ao mercado. Para as simulações, esse parâmetro afeta somente a precificação do risco do crédito no spread agregado, conforme a equação (15), sem afetar diretamente as demais variáveis endógenas.

\footnotetext{
${ }^{8}$ Foi aplicada uma aproximação de Taylor de $1^{\text {a }}$ ordem para log-linearizar o modelo em torno do estado estacionário. Essa aproximação ignora elementos de ordem mais alta na simulação da dinâmica do modelo.

${ }^{9} \mathrm{Na}$ classificação de crédito pelo rating AA não há exigência para constituir provisão para fazer face aos créditos de liquidação duvidosa.
} 
Tabela 1: Parâmetros Calibrados

\begin{tabular}{|c|c|c|c|}
\hline Parâmetro & Valor & Descrição & Fonte \\
\hline \multicolumn{4}{|l|}{ Famílias } \\
\hline$\beta$ & 0,9890 & \multirow{4}{*}{$\begin{array}{l}\text { Taxa de Desconto } \\
\text { Hábito do Consumo } \\
\text { Participação do Traba- } \\
\text { lho na Utilidade } \\
\text { Inverso da elasticidade } \\
\text { de Frisch da Oferta de } \\
\text { Trabalho }\end{array}$} & Castro et al. (2015) \\
\hline$h$ & 0,7544 & & Castro et al. (2015) \\
\hline$\chi$ & 3,5140 & & Silva \& Divino (2013) \\
\hline$\varphi$ & 0,1030 & & Silva \& Divino (2013) \\
\hline \multicolumn{4}{|c|}{ Instituições Financeiras } \\
\hline$\lambda$ & 0,2800 & $\begin{array}{l}\text { Fração do capital que } \\
\text { pode ser desviada } \\
\text { Transferência de recur- }\end{array}$ & Kornelius \& Divino (2015) \\
\hline$\omega$ & 0,0009 & $\begin{array}{l}\text { sos para os novos ban- } \\
\text { cos }\end{array}$ & Kornelius \& Divino (2015) \\
\hline$\theta$ & 0,9750 & $\begin{array}{l}\text { Taxa de sobrevivência } \\
\text { dos bancos }\end{array}$ & Kornelius \& Divino (2015) \\
\hline$\kappa_{D}$ & 2,4960 & $\begin{array}{l}\text { Intensidade do custo de } \\
\text { default }\end{array}$ & Silva \& Divino (2013) \\
\hline$\rho_{k}$ & 0,5884 & $\begin{array}{l}\text { Parcela dos emprésti- } \\
\text { mos sobre a qual incide } \\
\text { o risco de default }\end{array}$ & Cálculo próprio \\
\hline \multicolumn{4}{|c|}{ Firmas de Bens Intermediários } \\
\hline$\alpha$ & 0,3240 & $\begin{array}{l}\text { Participação efetiva de } \\
\text { capital na função de } \\
\text { produção }\end{array}$ & Silva \& Divino (2013) \\
\hline$\delta$ & 0,0250 & $\begin{array}{l}\text { Taxa de depreciação em } \\
\text { função do nível de utili- } \\
\text { zação do capital }\end{array}$ & Cavalcanti \& Vereda (2011) \\
\hline \multicolumn{4}{|c|}{ Firmas de Bens de Capital } \\
\hline$\eta_{\text {inv }}$ & 3,4200 & 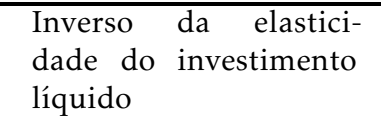 & Castro et al. (2015) \\
\hline \multicolumn{4}{|c|}{ Firmas de Bens Finais } \\
\hline$\varepsilon$ & 4,1670 & $\begin{array}{l}\text { Elasticidade de substi- } \\
\text { tuição }\end{array}$ & Gertler \& Karadi (2011) \\
\hline$\gamma$ & 0,7400 & $\begin{array}{l}\text { Probabilidade de man- } \\
\text { ter os preços fixos }\end{array}$ & Castro et al. (2015) \\
\hline$\gamma_{p}$ & 0,3300 & $\begin{array}{l}\text { Medida de indexação } \\
\text { de preços }\end{array}$ & Castro et al. (2015) \\
\hline \multicolumn{4}{|l|}{ Governo } \\
\hline$\kappa_{\pi}$ & 2,4300 & $\begin{array}{l}\text { Coeficiente da inflação } \\
\text { na regra de Taylor } \\
\text { Coeficiente do hiato do }\end{array}$ & Castro et al. (2015) \\
\hline$\kappa_{y}$ & 0,1500 & $\begin{array}{l}\text { Coeficiente do hiato do } \\
\text { produto na regra de } \\
\text { Taylor }\end{array}$ & Castro et al. (2015) \\
\hline$\rho_{i}$ & 0,79 & $\begin{array}{l}\text { Parâmetro de suaviza- } \\
\text { ção da regra de Taylor }\end{array}$ & Castro et al. (2015) \\
\hline$\rho_{p}$ & 0,79 & $\begin{array}{l}\text { Coeficiente } \\
\text { choque na probabili- } \\
\text { dade de pagamento }\end{array}$ & Calibração própria \\
\hline
\end{tabular}




\subsection{Choque de Política Monetária}

A Figura 1 ilustra as respostas a um choque na política monetária representado por um aumento de $0,25 \%$ na taxa básica de juros da economia. As linhas representam os desvios percentuais do estado estacionário das principais variáveis do modelo em resposta a esse choque exógeno não antecipado. O caso "sem risco de crédito e sem requerimento de compulsório" corresponde ao benchmark. A análise não busca ser exaustiva sobre as combinações possíveis desses 2 elementos porque alguns casos já foram contemplados em outros trabalhos. Assim, o caso "sem risco de crédito e com requerimento de compulsório" foi avaliado por Kornelius \& Divino (2015), embora a abordagem aqui apresentada seja mais ampla por considerar também a remuneração concedida pela Autoridade Monetária ao compulsório retido, o que não foi avaliado por aqueles autores. Já o caso "com risco de crédito e sem requerimento de compulsório" foi contemplado por Silva \& Divino (2013). Além disso, o foco desse trabalho é na relação entre risco de crédito e a política monetária, conduzida tanto de forma convencional, com a taxa nominal de juros servindo como instrumento de política, quanto não-convencional, com base em regras alternativas para a alíquota de requerimento compulsório.

A linha contínua corresponde aos efeitos do choque no modelo original de Gertler \& Karadi $(2011)^{10}$. Nota-se que, com o choque, os juros sofrem um aumento imediato que, devido à suavização presente na Regra de Taylor, vai reduzindo até convergir para o estado estacionário. Esse choque causa um aumento da taxa dos depósitos bancários em relação ao seu equilíbrio de $0,28 \%$, o que eleva o custo de captação dos bancos. Com taxas mais altas, o investimento torna-se mais caro, ocasionando uma redução da demanda por capital e, consequentemente, uma queda na demanda por crédito. Esta queda do crédito provoca contração no nível de produto da economia e impacta negativamente as horas trabalhadas.

De forma semelhante, as altas taxas de juros também impactam negativamente no consumo, o que tende a criar excesso de oferta sobre a demanda, forçando as firmas a reduzirem os preços e, por conseguinte, levando a uma queda na inflação. Por outro lado, a diminuição do consumo conjugada com taxas de juros mais altas estimulam a poupança, que é realizada mediante depósitos nas instituições financeiras. A diminuição da produção das firmas resulta em uma queda da taxa de juros dos empréstimos no momento do choque, tendo em vista que esta taxa reage com um período de defasagem ${ }^{11}$. Entretanto, no período seguinte ao choque, a queda na demanda por crédito, bem como a elevação do custo com captação, resulta em aumento da taxa dos empréstimos em $0,37 \%$ (taxa total crédito). Dado que esse aumento se dá de forma mais que proporcional ao encarecimento do custo de captação, o spread bancário eleva-se.

Quanto aos passivos bancários, devido à queda do valor de mercado do capital, o capital próprio das instituições financeiras também reduz, confirmando a identidade do balanço dos bancos, segundo a qual $Q_{t} S_{t}=B_{t+1}+N_{t}$, e impactando no aumento do grau de alavancagem das instituições. Para re-

\footnotetext{
${ }^{10}$ Outros trabalhos realizados para a economia brasileira, tais como Kornelius \& Divino (2015), Vasconcelos \& Divino (2012) e Castro et al. (2015) obtiveram resultados semelhantes.

${ }^{11}$ A taxa de juros dos empréstimos é uma variável em expectativa, pois os empréstimos são pós-fixados, isto é, o valor efetivo da taxa de juros só é conhecido no período seguinte à concessão do crédito.
} 
Figura 1: Funções Impulso Resposta a um Choque de Política Monetária
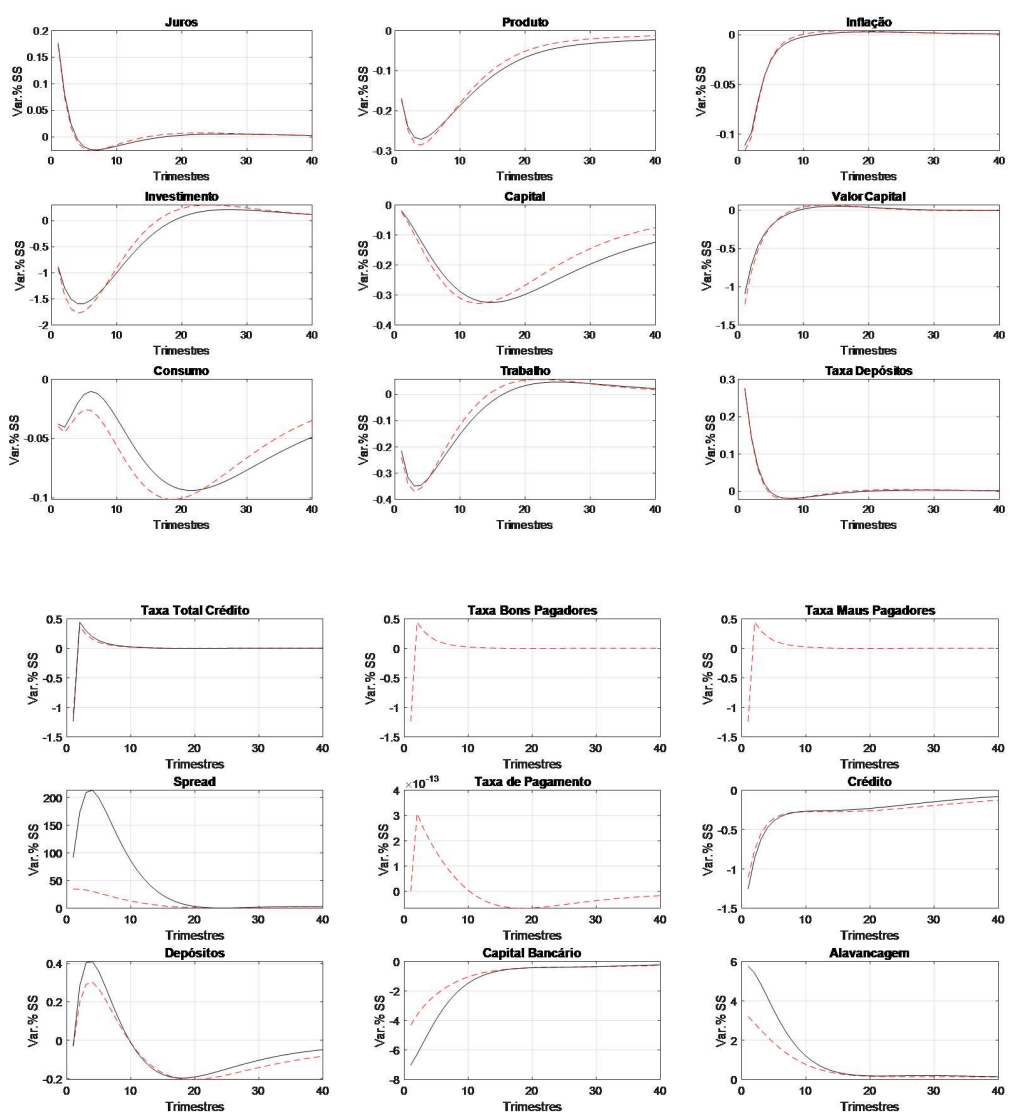

- Economia sem risco de crédito e sem requerimento compulsório
---- Economia com risco de crédito e com requerimento compulsório

duzir a alavancagem e recompor o capital próprio, os bancos reduzem a taxa paga aos depósitos, de modo a restringir a demanda e impactar no volume captado. Logo, na medida em que a taxa dos depósitos vai reduzindo, a taxa de juros da economia vai convergindo ao estado estacionário. Com um custo de captação menor, os bancos podem diminuir as taxas dos empréstimos, promovendo a recuperação da demanda por crédito. Com isso, o investimento volta a crescer, elevando também os níveis de produto e consumo da economia. Uma vez que ocorre a retomada do crédito, o patrimônio líquido das instituições financeiras volta a subir e, assim, o índice de alavancagem dos bancos torna-se menor.

A linha tracejada ilustra as respostas a esse mesmo choque considerando o modelo com risco de crédito e recolhimentos compulsórios. Da mesma forma que no modelo original (linha contínua), a taxa básica de juros sofre um aumento imediato que é gradualmente amortizado até convergir ao estado estacionário. Ocorre, então, um aumento instantâneo da taxa dos depósitos bancários de $0,28 \%$, elevando a demanda por este tipo de aplicação financeira e 
encarecendo a captação bancária. No entanto, por considerar os recolhimentos compulsórios, o volume de depósitos dessa versão do modelo sofre um aumento superior ao original, de modo a compensar a queda na liquidez causada pelos compulsórios.

De modo similar ao modelo original, ocorre uma queda nos investimentos, no capital e no nível de produto da economia. Com uma produção menor, as horas trabalhadas são reduzidas, assim como o consumo e a inflação. Como resultado da relação negativa entre a taxa de juros dos empréstimos das firmas do tipo 1, "más" pagadoras, e a taxa de pagamento do crédito, e tendo em vista o custo marginal com default incorrido por esta firma, a alta da taxa nos juros tem um efeito negativo sobre a taxa de pagamento dos empréstimos, que sofre uma variação negativa pequena de $0,008 \%$ no momento do choque. Essa variação, apesar de baixa, ocorre, principalmente, devido ao encarecimento do crédito, que é pós-fixado, e à redução do nível de produto. Esses fatores contribuem para a redução da capacidade de pagamento das firmas que incorrem em maior risco de default.

As taxas de juros dos bons e maus pagadores caem somente no momento do choque, mas elevam logo em seguida e convergem ao equilíbrio. Isso ocorre porque essas taxas entram nas equações (11) e (14) em valor esperado de $(t+1)$ com base no conjunto de informações disponível no período corrente. Assim, o aumento inesperado da taxa básica de juros no período corrente em decorrência do cheque de política monetária irá impactar naquelas taxas de juros somente em $(t+1)$. Esse efeito ocorre conforme o esperado, pois ambas aumentam. As magnitudes são iguais porque a diferença entre as equações (11) e (14) está na taxa de pagamento, que entra na taxa dos maus pagadores, (11), mas não na taxa dos bons pagadores, (14). Como a taxa de pagamento não depende diretamente da taxa de juros da política monetária pela equação (10) e pouco se altera em resposta ao choque monetário, não há diferença relevante nas respostas das taxas de juros dos bons e maus pagadores.

Ao considerar risco de default no modelo, a relação negativa entre a taxa de juros dos empréstimos e a taxa de pagamento do crédito passa a operar como uma compensação para o banco pelas perdas com o default, pois, a redução na taxa de pagamento - elevação do default - eleva a taxa de juros dos empréstimos. Logo, devido à queda da taxa de pagamento, a taxa dos empréstimos das firmas do tipo 1 sobe mais do que no modelo original, elevando também a taxa de juros agregada dos empréstimos, que é composta pela ponderação entre taxas dos "bons" e dos "maus" pagadores, que chega a $0,44 \%$ no período posterior ao choque. Por essa razão, o spread bancário no modelo com risco de default cresce acima do modelo original. O aumento dos depósitos bancários e a redução mais acentuada no nível de concessões de crédito provocam uma maior queda no capital próprio bancário, respeitando a identidade de balanço.

Pode-se concluir que a taxa de pagamento dos empréstimos é pró-cíclica ${ }^{12}$, indicando que o default aumenta em período de recessão econômica. Dessa forma, o custo mais elevado do crédito, devido ao risco de default, resulta em efeitos recessivos mais danosos sobre a economia.

\footnotetext{
${ }^{12}$ Outros artigos como Silva \& Divino (2013), Takamura (2013) e Marins \& Neves (2013) também encontraram uma taxa de default anticíclica.
} 


\subsection{Choque na Taxa de Pagamento dos Empréstimos}

A Figura 2 reporta as respostas a diferentes choques na taxa de pagamento dos empréstimos, que variam em $0,25 \%, 1,0 \%, 2,5 \%$ e 5,0\%, com o objetivo de verificar como a intensidade desse choque afeta a dinâmica da economia. Para elevar o índice de pagamento das dívidas junto aos bancos, as firmas devem obter esses recursos mediante a redução nos gastos com investimentos. Assim, o aumento inesperado na taxa de pagamento dos empréstimos retira recursos da economia, de maneira a abreviar o investimento em capital. Com isso, a demanda por crédito contrai-se, reduzindo a taxa total de crédito no momento do choque. O menor investimento das firmas causa retração das taxas de juros e de inflação. Entretanto, a queda na inflação é mais do que proporcional ao decréscimo dos juros nominais, ocasionando elevação dos juros reais - taxa de remuneração dos depósitos.

O aumento na taxa de depósitos, por sua vez, traz mais atratividade a essa aplicação financeira, elevando a poupança da economia e contribuindo para reduzir ainda mais a inflação. De modo oposto, com taxas mais altas, os depósitos tornam-se mais caros para as instituições financeiras, que devem repassar esse custo mais elevado sob a forma de aumento da taxa de juros dos empréstimos. Considerando que a taxa de crédito dos "maus" pagadores é influenciada pelo aumento da taxa de pagamento, a taxa das firmas do tipo 1 fica praticamente inalterada nas quatro simulações realizadas. Isto ocorre porque, com o aumento do pagamento dos empréstimos, a receita de crédito do banco proveniente desse tipo de firma expande, reduzindo a necessidade de elevar a taxa de juros dos empréstimos para compensar o encarecimento do custo de captação. Por outro lado, a taxa de crédito dos "bons" pagadores não é impactada pela taxa de pagamento e, por isso, eleva-se como forma de corrigir a queda no resultado das instituições financeiras em decorrência de um maior custo de captação. Contudo, devido à ponderação entre as taxas dos "bons" e "maus" pagadores, a taxa de juros agregada do crédito sofre uma variação pequena. Essa variação, no entanto, é suficiente para onerar os novos investimentos, que se tornam menores, limitam a aquisição de capital e reduzem o nível de produto da economia. Na medida em que a taxa de pagamento volta para seu valor inicial, os juros e a inflação crescem, causando queda na taxa dos depósitos (juros reais). Dado que essa queda é superior ao aumento da taxa do crédito, o spread bancário aumenta até o momento em que ambas as taxas retornam para seus valores de estado estacionário. Com isso, o crédito e os depósitos convergem para o equilíbrio, juntamente com as demais variáveis do modelo.

Percebe-se que o aumento da taxa de pagamento do crédito, o que corresponde a um choque negativo no default dos empréstimos, causa um efeito recessivo na economia, visto que, para o pagamento da dívida, é necessário retirar recursos que seriam destinados aos investimentos das firmas. As quatro simulações realizadas evidenciam o mesmo efeito em todos os percentuais aplicados ao choque, indicando que, quanto maior a elevação exógena na taxa de pagamento, maior será o volume de recursos retirados dos novos investimentos e mais intenso será o efeito recessivo sobre a economia. 
Figura 2: Funções Impulso Resposta a choques na Taxa de Pagamento
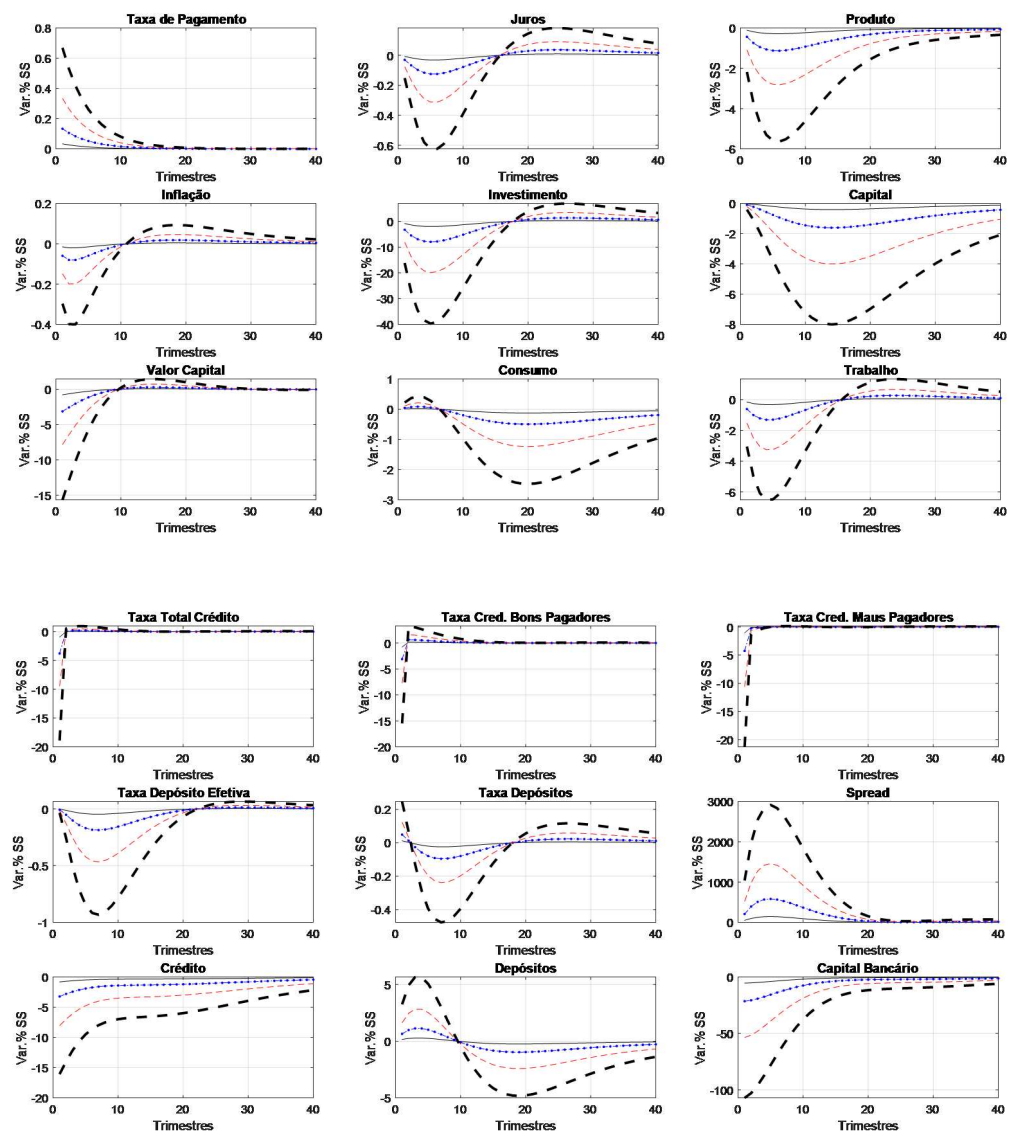

$\begin{array}{ll}-\cdots- & \text { Choque de } 5,0 \% \text { na taxa de pagamento dos empréstimos } \\ -\cdots-- & \text { Choque de } 2,5 \% \text { na taxa de pagamento dos empréstimos } \\ -\cdots-\cdot & \text { Choque de } 1,0 \% \text { na taxa de pagamento dos empréstimos } \\ - & \text { Choque de } 0,25 \% \text { na taxa de pagamento dos empréstimos }\end{array}$

\subsection{Recolhimento Compulsório}

Para avaliar os efeitos de alterações exógenas nas regras de recolhimentos compulsórios sobre o risco de crédito e demais variáveis, são considerados três cenários distintos. Os dois primeiros tratam de uma alíquota fixa no tempo e respostas ao choque de Política Monetária, considerando diferentes alíquotas e taxas de remuneração dos depósitos compulsórios. O terceiro refere-se à política anticíclica em relação ao crédito e analisa os efeitos de um choque nos depósitos compulsórios sob diferentes pesos para os desvios do crédito. Cabe ressaltar que, conforme a equação (5), se $\kappa_{R R}=1$, então $R_{t}^{*}=R_{t}$ e a presença de compulsório no modelo não altera a taxa de remuneração dos depósitos, que é igual ao custo efetivo do funding. Por isso, considerou-se que a remuneração dos depósitos compulsórios é nula, fazendo $\kappa_{R R}=0$, de forma a amplificar os efeitos do choque.

A Figura 3 reporta as respostas dinâmicas ao choque de Política Monetária 
para alíquotas de depósitos compulsórios de 10, 36 e 45\%. ${ }^{13}$ Diante de um aumento não antecipado da taxa de juros, ocorre uma elevação imediata da taxa dos depósitos bancários, causando encarecimento do custo de captação dos bancos. As taxas de juros mais altas tornam o investimento das firmas mais oneroso, ocasionando uma redução na demanda por capital, queda em seu preço e, assim, uma diminuição na demanda por crédito. Como isso, o nível de produção da economia se reduz, impactando negativamente nas horas trabalhadas.

Figura 3: Choque de Política Monetária sob Diferentes Alíquotas de Compulsório
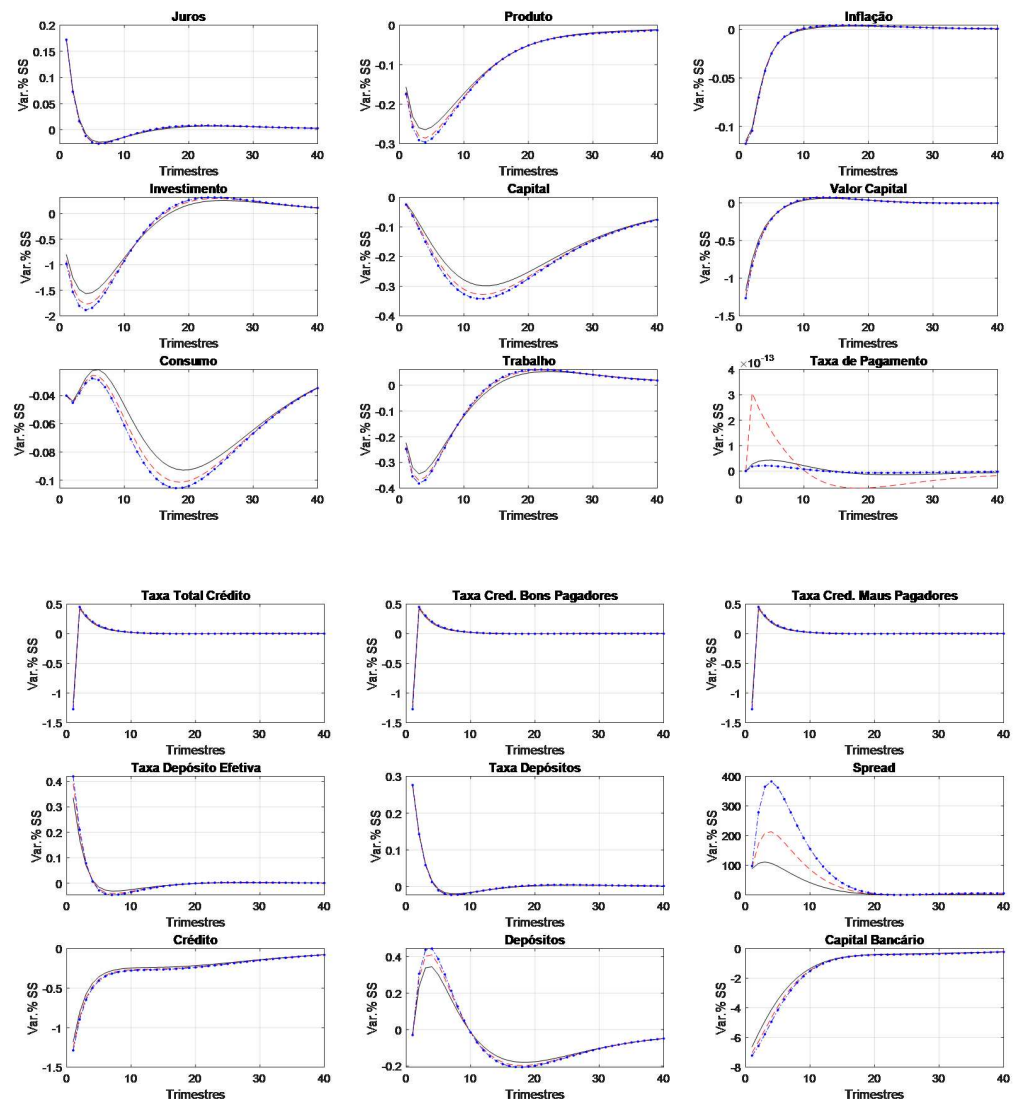

- Compulsório de $10 \%$, sem remuneração

...... Compulsório de $45 \%$, sem remuneração

Do mesmo modo, as altas taxas de juros também impactam negativamente no consumo, o que tende a criar excesso de oferta sobre a demanda, forçando as firmas a reduzir os preços e promovendo queda da inflação. Em contrapartida, a diminuição do consumo em conjunto com taxas de juros mais altas,

\footnotetext{
${ }^{13}$ As alíquotas de $36 \%$ e $45 \%$ referem-se, respectivamente, aos valores utilizados para os depósitos a prazo e à vista. Já o valor de $10 \%$ refere-se à alíquota adicional do depósito a prazo.
} 
elevam a poupança realizada mediante depósitos nas instituições financeiras. A contração da produção das firmas, assim como do valor de seu capital, resulta em menores taxas de juros para os empréstimos no momento do choque, dado que essa taxa reage com um período de defasagem. Contudo, no período posterior ao choque, a queda na demanda por crédito e a elevação do custo com captação ocasionam o crescimento da taxa dos empréstimos. Como o aumento se dá de forma mais que proporcional ao encarecimento do custo de captação, o spread bancário eleva-se. O capital próprio das instituições financeiras também se reduz em virtude da queda no valor do capital, provocando aumento do grau de alavancagem das instituições.

Ao avaliar os três valores para a alíquota dos depósitos compulsórios, verificase que, na medida em que a alíquota aumenta, o efeito do choque de taxa de juros sobre a economia torna-se mais intenso. Isso ocorre porque uma alíquota maior eleva o custo do funding para a instituição financeira, que repassa essa despesa adicional mediante elevação da taxa de juros dos empréstimos. Então, quanto mais essa taxa aumenta, maior é o efeito de queda sobre a taxa de pagamento dos empréstimos, o que acaba por reforçar a elevação dos juros. Assim, há um efeito inverso da alíquota de compulsório sobre a taxa de pagamento das firmas, sugerindo que aumentos naquela alíquota elevam a probabilidade de default das firmas devido à redução de liquidez que provoca por meio do encarecimento do crédito. Esse encarecimento do investimento traz como consequência a contração do nível de produto da economia.

Além disso, de acordo com a equação (2), alíquotas mais elevadas aumentam a retirada de liquidez da economia, que deve ser compensada com maiores volumes de depósitos bancários. Isso aumenta a participação do capital de terceiros na composição total do capital do banco, causando elevação do grau de alavancagem das instituições. Há uma relação direta entre alíquota de compulsório e o grau de alavancagem dos bancos. Quanto maior for a alíquota do depósito compulsório, maior será o aumento do grau de alavancagem e mais o banco deve baixar a taxa paga aos depósitos, de forma a recompor o capital próprio.

Em relação à inflação, nota-se que, independentemente da alíquota analisada, a resposta ao choque permanece muito semelhante. Como a inflação é mais sensível a modificações no preço (valor) do capital do que a quedas em seu estoque, temos que o choque na taxa de juros causa uma oscilação pequena no valor do capital e a inflação quase não responde a variações na alíquota de compulsório. Então, conclui-se que, na presença de um choque de política monetária, alterações na alíquota do depósito compulsório impactam no nível de produto da economia, de forma a amplificar os efeitos do choque, devido à reação mais intensa do banco para recompor seu capital. Contudo, alterações nas alíquotas do requerimento compulsório não impactam na resposta da inflação, pois têm impacto pequeno sobre o preço do capital ${ }^{14}$.

A Figura 4 também apresenta as respostas da economia a um choque na política monetária, variando, porém, as remunerações dos depósitos compulsórios em $0 \%, 25 \%, 50 \%, 75 \%$ e $100 \%$ de $R_{t}$. Verifica-se que, quanto menor a remuneração dos compulsórios, maior é a resposta da economia. Isso ocorre porque essa remuneração possui efeito negativo sobre a despesa de captação

\footnotetext{
${ }^{14}$ Resultados semelhantes foram encontrados em Kornelius \& Divino (2015) em uma versão do modelo que não inclui o risco de crédito.
} 
efetiva, sendo que, quanto menor a remuneração, maior será o custo adicional do funding, conforme a equação (5).

Figura 4: Choque na Política Monetária sob Diferentes Remunerações do Compulsório
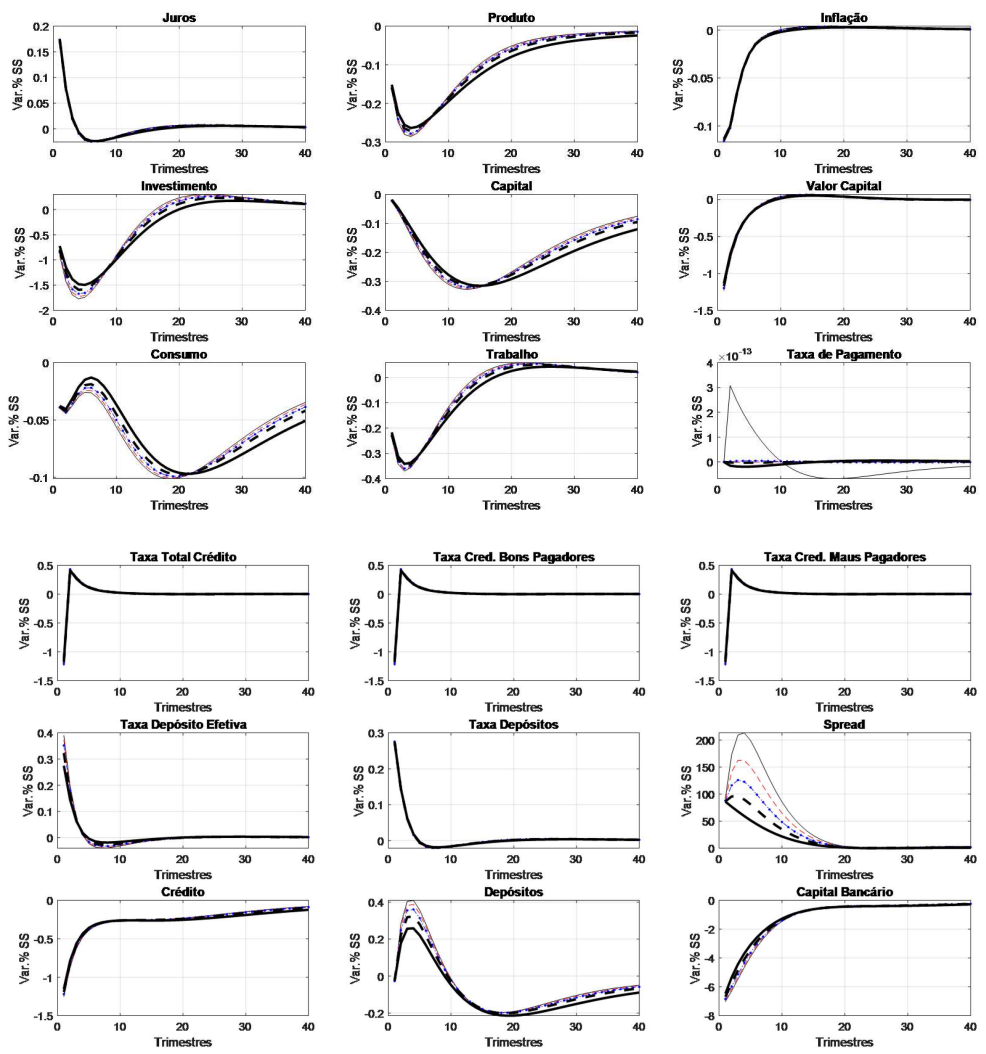

- Remuneração dos Depósitos Compulsórios de $100 \%$ de $R_{t}$

- - - Remuneração dos Depósitos Compulsórios de $75 \%$ de $R_{t}$

-..... Remuneração dos Depósitos Compulsórios de $50 \%$ de $R_{t}$

-..-. Remuneração dos Depósitos Compulsórios de $25 \%$ de $R_{t}$

— Remuneração dos Depósitos Compulsórios de $0 \%$ de $R_{t}$ - sem remuneração

Assim como na simulação anterior, as elevações do custo do funding são repassadas às firmas por meio de elevação das taxas de juros dos empréstimos, causando encarecimento dos investimentos e a consequente contração do nível de atividade da econômica. Esse efeito é reforçado pela queda na taxa de pagamento, que é maior quando a remuneração do compulsório é menor. Já em relação à inflação, as alterações na remuneração do depósito compulsório não impactam na resposta ao choque de política monetária, posto que o preço do capital sofre uma variação pequena. Para avaliar os efeitos de uma perturbação na alíquota dos depósitos compulsórios, foi aplicado um choque exógeno à regra anticíclica definida pela equação (7), conforme já discutido na seção 2.1. Caso $\kappa_{\tau}=0$, não existe regra anticíclica para o depósito compulsório, que será dado por uma alíquota fixa $\tau \equiv 0,36^{15}$. No entanto, com $\kappa_{\tau}>0$

\footnotetext{
${ }^{15} \mathrm{~A}$ alíquota de $36 \%$ refere-se ao valor utilizado para os depósitos a prazo.
} 
a regra anticíclica estará ativa e dependerá do peso atribuído aos desvios do crédito em relação ao seu nível de estado estacionário. A Figura 5 reporta as respostas a um choque de $1,0 \%$ na alíquota dos requerimentos compulsórios, considerando valores diferenciados para $\kappa_{\tau}{ }^{16}$.

Figura 5: Funções Impulso Resposta a um Choque na Regra de Compulsório
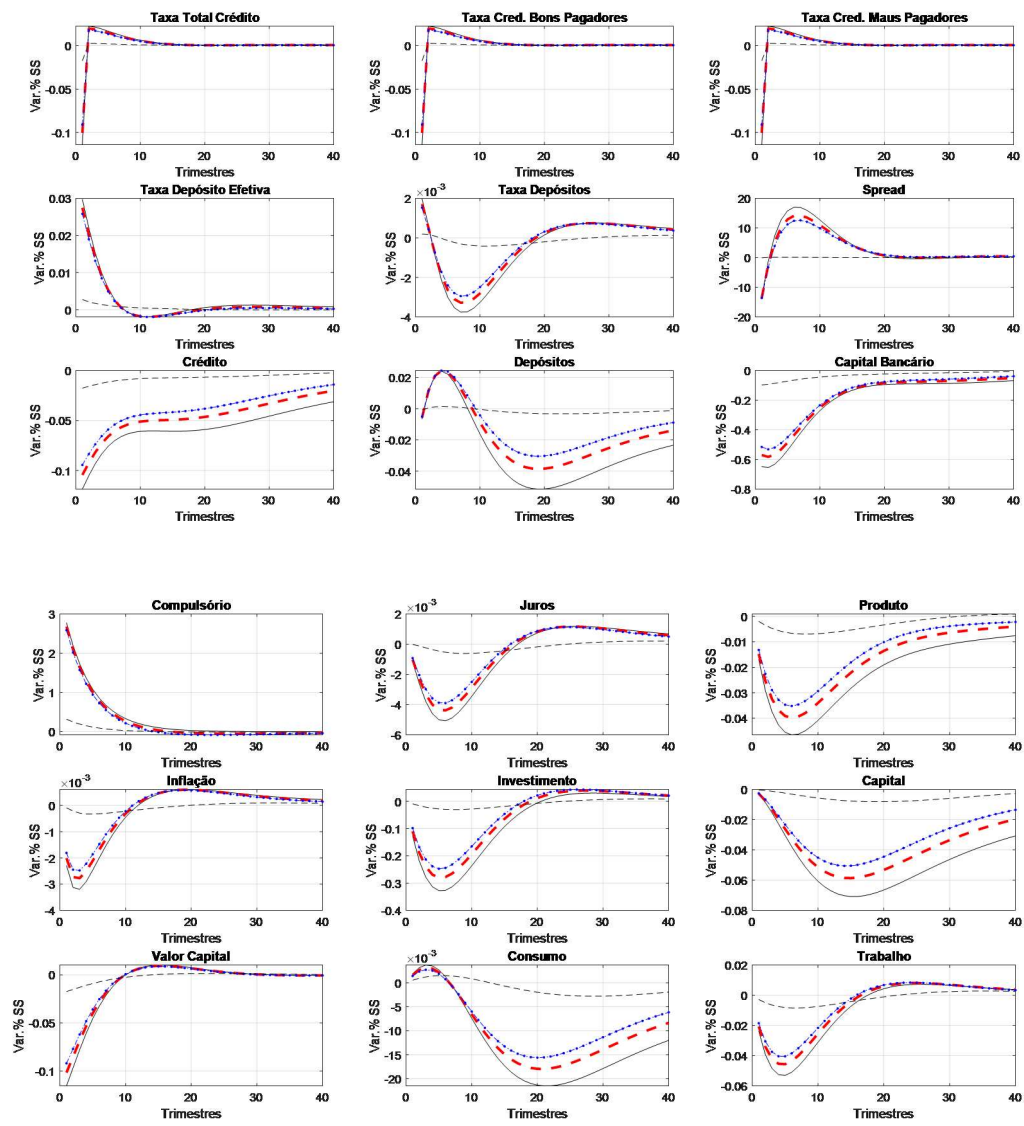

$$
\begin{aligned}
& \text { Compulsório de } 36 \% \text {, sem remuneração, } \kappa_{\tau}=0 \\
& --- \text { Compulsório de } 36 \% \text {, sem remuneração, } \kappa_{\tau}=0,5 \\
& -\cdots \cdots
\end{aligned}
$$

O aumento não antecipado na alíquota dos requerimentos compulsórios implica na retirada extraordinária de liquidez da economia, tendo como consequência a queda dos juros (nominais) e da inflação. Porém, como essa última cai com mais intensidade, ocorre uma elevação da taxa dos depósitos (juros reais) no momento do choque. Aliado a isso, o aumento da alíquota do compulsório eleva ainda mais a taxa de depósito efetiva, tornando mais caro o custo do funding das instituições financeiras. Isto traz como resultado a redução da oferta de crédito da economia, o que impacta na diminuição dos

\footnotetext{
${ }^{16}$ No processo $\operatorname{AR}(1)$ para $\epsilon_{\tau_{t}}$, utilizou-se o fator autorregressivo de 0,79.
} 
investimentos, do preço do capital, e do nível de atividade econômica. À medida em que o choque vai se dissipando como um processo $\mathrm{AR}(1)$ estacionário, a despesa de captação do banco reduz, possibilitando a retomada da oferta de crédito. Com isso, os investimentos aumentam, elevando o valor do capital e o produto da economia.

As linhas tracejadas representam a agressividade da política anticíclica do compulsório em relação a desvios do crédito. Por essas regras, como o montante ofertado de empréstimos bancários cai abaixo de seu nível de estado estacionário, valores mais altos de $\kappa_{\tau}$ representam respostas mais agressivas de queda na alíquota aplicada. Isso induz a recuperações mais rápidas do crédito e da atividade econômica. A redução mais rápida do compulsório impacta na queda mais veloz do custo de captação do banco e em uma retomada mais ágil do crédito bancário, dos investimentos e do nível de produção da economia.

As menores alíquotas do compulsório também resultam na recuperação mais acelerada da inflação, pois a retirada da liquidez da economia tende a desacelerar, possibilitando a restauração dos níveis iniciais dos juros nominais. Dessa forma, conforme já relatado por Kornelius \& Divino (2015), uma regra anticíclica mais agressiva do depósito compulsório em relação ao crédito amplifica os efeitos de um choque na política monetária.

\section{Conclusão}

Esse artigo considerou uma modelagem de risco de credito endógeno e investigou a relação entre o risco de default e a política monetária, conduzida tanto de forma convencional, com a utilização a taxa nominal de juros como instrumento de política, quanto não-convencional, baseada em regras para o requerimento de depósitos compulsórios. Foram analisados os efeitos e os canais de transmissão de choques exógenos no risco de crédito, taxa nominal de juros e alíquota de compulsório sobre a estabilidade de preços e o ciclo econômico. A abordagem baseou-se em uma versão modificada do modelo de Gertler \& Karadi (2011), que incluiu fricções financeiras, requerimento de depósitos compulsórios e risco de crédito em um ambiente unificado. A probabilidade de default das firmas foi derivada endogenamente, em conformidade com Walque et al. (2010) e Silva \& Divino (2013). O modelo modificado permitiu a análise da qualidade dos tomadores de crédito, introduzindo taxas diferenciadas de juros para os empréstimos. O modelo foi calibrado para a economia brasileira, que enfrentou risco de crédito e utilizou ativamente os depósitos compulsórios como instrumento de política monetária no período recente.

Os resultados das simulações para a economia brasileira indicaram que a taxa de pagamento dos empréstimos é pró-cíclica, sugerindo que o default aumenta em período de recessão econômica. Isto ocorre porque o aumento não antecipado da taxa de juros da economia causa o encarecimento do crédito e a redução do nível de produto. Esses fatores agem de forma a reduzir a capacidade de pagamento das firmas que incorrem em maior risco de default. Assim, a relação negativa entre a taxa de juros dos empréstimos e a taxa de pagamento do crédito funciona como uma compensação para o banco pelas perdas com o default. Além do mais, o custo mais elevado para o crédito, devido ao risco de default, resulta em efeitos mais danosos, em termos de produto, do que no modelo original, sem risco de crédito. 
A análise também contemplou diferentes valores de choques na taxa de pagamento dos empréstimos. Percebeu-se que, o aumento não antecipado da taxa de pagamento do crédito tem um efeito recessivo na economia, visto que, para o pagamento antecipado da dívida, é necessário retirar recursos dos investimentos das firmas. As simulações realizadas indicam que, quanto maior a elevação na taxa de pagamento, maior será o volume de recursos retirados dos novos investimentos e mais intenso será o efeito recessivo sobre a economia. Portanto, tanto a redução inesperada na taxa de pagamento dos empréstimos, evidenciada pelo choque monetário, quanto o aumento não antecipado dessa taxa, provocam efeitos recessivos na economia, indicando que deve existir uma taxa de pagamento ótima que não suscite esse resultado.

O requerimento de depósitos compulsórios pela Autoridade Monetária afeta a dinâmica das variáveis, especialmente quando esses depósitos não são remunerados e a regra de política anticíclica para a alíquota de compulsório responde mais agressivamente a desvios no crédito. Diante de um choque exógeno na regra de compulsório, pesos maiores para o componente anticíclico resultam em efeitos mais brandos para a economia como um todo, pois há uma suavização maior dos desvios do crédito nesse caso. A redução mais rápida do compulsório diante dos pesos maiores na regra de política leva a uma queda mais acentuada no custo de captação do banco e, com isso, a uma retomada mais ágil do crédito bancário, dos investimentos e do nível de atividade econômica. Além disso, há uma oscilação mais branda da taxa de inflação, pois os efeitos sobre a liquidez e a taxa nominal de juros tendem a ser menores, possibilitando uma convergência mais rápida ao estado estacionário. Como o risco de default não é afetado pela maior agressividade da regra de compulsório, enquanto há ganhos na estabilidade de preços e da atividade econômica, essa regra anticíclica de compulsório emerge como uma alternativa à política monetária convencional.

Como sugestões para pesquisas futuras, destacamos a inclusão da política fiscal e a análise de sua interação com as políticas monetária e macroprudencial, já presentes no modelo. Indicamos, também, a estimação bayesiana dos parâmetros estruturais do modelo e o cômputo de funções impulso utilizando os parâmetros estimados. O setor financeiro também pode ser ampliado, estendendo os empréstimos bancários aos indivíduos. Algumas dessas sugestões, contudo, já são objeto de pesquisa em andamento.

\section{Agradecimentos}

Os autores agradecem os participantes no XLVI Encontro da ANPEC, XVII Latin American Workshop in Economic Theory e a dois avaliadores anônimos pelos valiosos comentários e sugestões. J. A. Divino agradece o apoio financeiro do CNPq. Os erros remanescentes são de responsabilidade exclusiva dos autores.

\section{Referências Bibliográficas}

Agénor, P. R., Alper, K. \& Silva, L. P. (2018), 'External shocks, financial volatility and reserve requirements in an open economy', Journal of International Money and Finance 83, 23-43. 
Areosa, W. D. \& Coelho, C. A. (2013), 'Utilizando um Modelo DSGE para Avaliar os Efeitos Macroeconômicos dos Recolhimentos Compulsórios no Brasil', Banco Central do Brasil .

Bernanke, B., Gertler, M. \& Gilchrist, S. (1996), 'The Financial Accelerator and the Flight to Quality', The Review of Economics and Statistics 78, 1-15.

Bernanke, B. S., Gertler, M. \& Gilchrist, S. (1999), The Financial accelerator in a quantitative business cycle framework, in 'Em Handbook of Macroeconomics, por J. B. Taylor, \& M. Woodford; Ed. 1; cap. 21', in Taylor, J. B. \& Woodford, M., eds, Handbook of Macroeconomics, vol. 1, cap. 21, pp. 1341-1393.

Carlstrom, C. \& Fuerst, T. (1997), 'Agency costs, Net Worth, and Business Fluctuations: a Computable General Equilibrium Analysis', American Economic Review 87, 893-910.

Carvalho, F. \& Castro, M. (2016), A Brazilian Perspective on Macroprudential and Monetary Policy Interaction, in in Carrière-Swallow, Y., Faruquee, H., Jacome, L. \& Srinivasan, K., eds, Challenges for central banking: perspectives from Latin America, Washington', DC: International Monetary Fund.

Carvalho, F., Castro, M. \& Costa, S. (2014), 'Traditional and Matter-of-fact Financial Frictions in a DSGE Model for Brazil: the Role of Macroprudential Instruments and Monetary Policy', BIS Working Papers 460.

Castro, M. R., Gouvea, S. N., Minella, A., Santos, R. C. \& Souza-Sobrinho, N. F. (2015), 'SAMBA: Stochastic Analytical Model with a Bayesian Approach', 35(2), 103-170.

Cavalcanti, M. A. F. H. \& Vereda, L. (2011), 'Propriedades dinâmicas de um modelo DSGE com parametrizações alternativas para o Brasil'.

Christensen, I. \& Dib, A. (2008), 'The Financial Accelerator in an Estimated New Keynesian model', Review of Economic Dynamics 11, 155-178.

Christiano, L., Eichenbaum, M. \& Evans, C. (2005), 'Nominal Rigidities and the Dynamic Effects of a Shock to Monetary Policy', Journal of Political Economy 113, 1-45.

Cúrdia, V. \& Woodford, M. (2010), 'Credit Spreads and Monetary Policy', Journal of Money Credit and Banking 42, 3-35.

De Graeve, F. (2008), 'The External Finance Premium and the Macroeconomy: US Post-WWII Evidence', Journal of Economic Dynamics and Control 32, 3415-3440.

Ferreira, L. \& Nakane, M. (2015), 'Macroprudential Policy in a DSGE Model: anchoring the countercyclical capital buffer', (407).

Gerali, A., Neri, L. S. \& Signoretti, F. M. (2010), 'Credit and Banking in a DSGE Model of the Euro Area', Journal of Money,Credit and Banking 42, 107141.

Gertler, M. \& Karadi, P. (2011), 'A model of unconventional monetary policy', Journal of Monetary Economics 58, 17-34. 
Glocker, C. \& Towbin, P. (2015), 'Reserve requirements as a macroprudential instrument - empirical evidence from Brazil', Journal of Macroeconomics $44,158-176$.

Iacoviello, M. (2005), 'House Prices, Borrowing Constraints, and Monetary Policy in the Business Cycle', American Economic Review 95, 739-764.

Kiyotaki, N. \& Moore, J. (1997), 'Credit cycles', Journal of Political Economy 105, 211-248.

Kiyotaki, N. \& Moore, J. (2019), 'Liquidity, Business Cycles, and Monetary Policy', Journal of Political Economy 127, 2926-2966.

Kornelius, A. \& Divino, J. A. (2015), 'Política Monetária e Compulsório em um Modelo DSGE com Friç̧ões Financeiras', Economia Aplicada 19, 579-610.

Marins, J. T. M. \& Neves, M. B. E. (2013), 'Credit Default and Business Cycles: an investigation of this relationship in the Brazilian corporate credit market'.

Montoro, C. \& Tovar, C. (2010), 'Macroprudential tools: Assessing the implications of reserve requirements in a DSGE model'.

Nunes, A. F. N. \& Portugal, M. S. (2018), 'Intermediários Financeiros e Política de Crédito em um Modelo DSGE para o Brasil', Revista Brasileira de Economia 72, 361-390.

Silva, M. S. \& Divino, J. A. (2013), 'The role of banking regulation in an economy under credit risk and liquidity shock', North American Journal of Economics and Finance 26, 266- 281.

Smets, F. \& Wouters, R. (2007), 'Shocks and frictions in U.S. business cycles: a Bayesian DSGE approach', American Economic Review 97, 586-606.

Takamura, T. (2013), 'A General Equilibrium Model with Banks and Default on Loans'.

Tavman, Y. Y. (2015), 'A comparative analysis of macroprudential policies', Oxford Economic Papers 67, 334-355.

Valli, M. \& Carvalho, F. (2010), 'Fiscal and monetary policy interaction: a simulation based analysis of a two-country New Keynesian DSGE model with heterogeneous households'.

Valli, M. \& Carvalho, F. (2011), 'Fiscal Policy in Brazil through the Lens of an Estimated DSGE model'.

Vasconcelos, B. F. B. \& Divino, J. A. (2012), 'O Desempenho Recente da Política Monetária Brasileira sob a Ótica da Modelagem DSGE'.

Walque, G., Olivier, P. \& Abdelaziz, R. (2010), 'Financial (in)stability, supervision and liquidity injections: a dynamic general equilibrium approach', The Economic Journal 120, 1234-1261. 